\title{
Desorption characteristics of total phosphorus and heavy metals from impervious urban surface sediments
}

\author{
LI YingXia ${ }^{1}{ }^{*},{\text { XIANG } \text { Li }^{2} \text {, TIAN Peng }}^{1}$ \& LIU JingLing ${ }^{1}$ \\ ${ }^{1}$ State Key Laboratory of Water Environment Simulation, School of Environment, Beijing Normal University, Beijing 100875, China; \\ ${ }^{2}$ Institute of Mountain Hazards and Environment, Chinese Academy of Sciences, Chengdu 610041, China
}

Received December 5, 2012; accepted March 1, 2013; published online May 14, 2013

\begin{abstract}
Dry sediments were collected from one roof and two roads in the central area of Beijing. The sediments were dry and wet sieved. The concentrations of total phosphorus (TP) and heavy metals were analyzed. The highest mass proportion of the dry sediments from the roads were between 125 and $300 \mu \mathrm{m}$ in diameter, while the roof sediments were much smaller, with $75 \%$ of the total sediment mass between 40 and $74 \mu \mathrm{m}$ in diameter. The concentrations of TP and heavy metals in the roof sediments were much higher than in the road sediments. The concentrations of the six heavy metals investigated had a similar order for all three sampling sites, with the $\mathrm{Zn}$ concentration always being the highest, followed by the $\mathrm{Mn}$ concentration, and the Ni concentration was always the lowest. After wet sieving, $76.9 \%$ to $91 \%$ of the TP in the sediments from the three sites remained in undesorbable particulate form, and $68.9 \%$ to $97 \%$ of the heavy metals were present in undesorbable particulate form. The concentrations of undesorbed heavy metals in the roof sediments tended to increase with increasing sediment size, but a similar trend was not found in the road sediments. This study shows that more attention should be given to the particulate matter in stormwater runoff, as reducing the amount of particulates will improve the efficiency of pollution control measures.
\end{abstract}

Beijing, desorption capacity, heavy metals, sediments, sieving, total phosphorus

Citation: Li Y X, Xiang L, Tian P, et al. Desorption characteristics of total phosphorus and heavy metals from impervious urban surface sediments. Chin Sci Bull, 2013, 58: 3357-3360, doi: 10.1007/s11434-013-5809-z

Stormwater is recognized as a significant pollution source in aquatic environments. Many studies have shown that a large number of pollutants are present in stormwater runoff $[1,2]$. Dry sediments on impervious surfaces in urban areas compose one of the most important sources of pollutants in stormwater and may enter runoff in dissolved, colloidal and particulate-bound forms during rainfall events [3-5]. The characteristics of pollutant transformation from dry sediments to dissolved, colloidal and particulate-bound forms are important for understanding pollutant behavior in stormwater [6-8]. Some research has been undertaken on dry sediment desorption $[9,10]$ and the results show that most of the total phosphorus (TP) is attached to the particulates after wet sieving. Further research work is required to elucidate the desorption capacity of various pollutants from

*Corresponding author (email: yingxia@bnu.edu.cn) dry sediments to better understand the pollutant transformation behavior from dry sediments to different forms in water. The objective of this study is to investigate the desorption behavior of TP and heavy metals in dry sediments collected from different types of urban areas and to understand the transformation of pollutants from dry sediments during rainfall. The results may assist in developing control strategies that target the trapping and immobilization of these sediments.

\section{Methodology}

\subsection{Sampling methodology}

Three sampling sites, one roof and two roads, were chosen around the city center of Beijing. The two road sites were on a campus road inside Beijing Normal University (BNU) 
and north 3rd-ring Street, which is approximately $0.2 \mathrm{~km}$ eastern of the cross of the north 3rd-ring street and Xingtan Road. These two roads have different traffic loads with average daily traffic (ADT) numbers of 3000 and 110000 cars per day, respectively. The roof chose was on a building inside the BNU campus. Sediment samples were collected using a Panasonic MC-CG663 vacuum cleaner between late August and early September 2007.

\subsection{Laboratory analysis}

A portion of the dry sediments collected from each sampling site were weighed and then dry sieved through a combination of nylon and metal sieves with mesh sizes of 1000 , $500,300,125,74$, and $40 \mu \mathrm{m}$. The masses of sediments in each size range were measured and the mass proportion was calculated.

A wet sieving procedure was conducted separately on the dry sediments collected from each site. Two grams of the dry sediment was added to $1 \mathrm{~L}$ distilled water and then sieved through a series of sieves with mesh sizes of 100, 40, 10 , and $0.45 \mu \mathrm{m}$. A $20 \mathrm{~mL}$ sample of filtrate was taken from the well-mixed liquid passed through each sieve. The concentrations of TP and heavy metals in each well-mixed filtrate sample were measured using the phosphorous-molybdenum blue spectra-photometric and inductively coupled plasma-mass spectrometry (ICP-MS) methods, respectively, in according to the National Environmental Protection Administration (NEPA) technical specification for soil environmental monitoring.

\section{Results and discussion}

\subsection{Dry sediment mass proportion}

The mass proportions of each size range obtained from the dry sieving are shown in Figure 1. The results show that for the road sediments, the highest mass proportions occurred for sediments with diameters between 125 and $300 \mu \mathrm{m}$, with $34 \%$ and $39 \%$ of the total sediment mass for the campus road and 3rd-ring street, respectively. The roof sediments were much smaller, and $75 \%$ of the total sediment mass had diameters between 40 and $74 \mu \mathrm{m}$. The reason for this discrepancy is most likely because roof sediments mainly come from dust in the air, while road sediments have more varied sources such as tire and pavement erosion.

\subsection{TP concentration in the filtrate passing through each sieve}

The TP concentration in the filtrate passing through each sieve is shown on Figure 2(a). This result shows that the roof sediments have much higher TP concentrations than do the road sediments. The TP concentration in the filtrate from the roof sediments passing through each sieve ranges

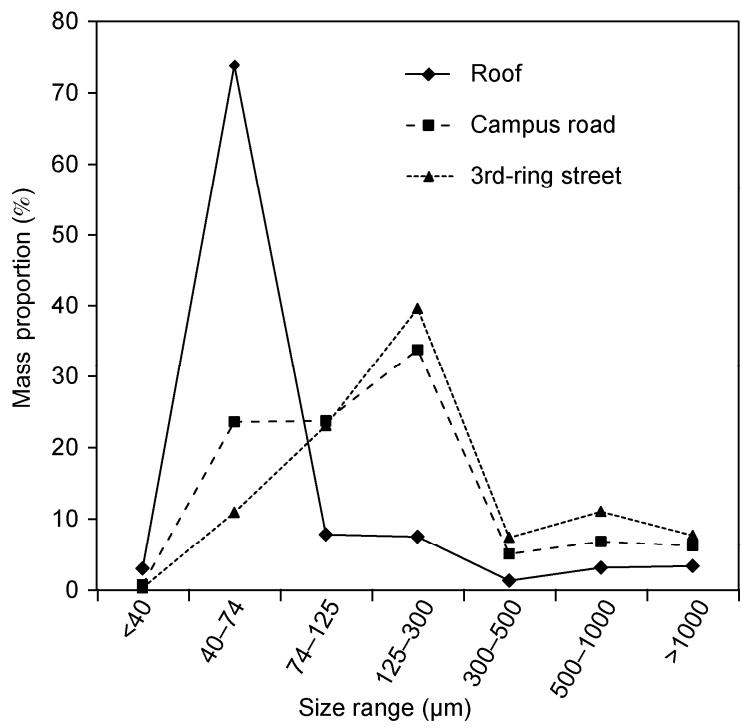

Figure 1 Dry sediment mass proportions in different size ranges.

from 0.055 to $0.54 \mathrm{mg} / \mathrm{L}$, while the TP concentrations in the filtrates of the campus road sediments and 3rd-ring street sediments are 0.023 to $0.23 \mathrm{mg} / \mathrm{L}$, and 0.062 to $0.16 \mathrm{mg} / \mathrm{L}$, respectively. Figure 2(b) shows the concentrations of particulate TP in different size ranges that were not desorbed during the wet sieving procedure. This undesorbed concentration is calculated by subtracting the TP concentration in the filtrate passing through a certain sized mesh from the TP concentration in the filtrate passing through the immediately larger mesh size sieve shown on Figure 2(a). The results show that the undesorbed particulate TP concentration on sediments between 0.45 and $100 \mu \mathrm{m}$ from the roof is much higher than on sediments of any same size from the two roads. The proportions of undesorbable TP from the different particulate samples are $90.4 \%, 91.0 \%$ and $76.9 \%$ for sediments from the roof, the campus road, and 3rd-ring street, respectively. Figure 2 shows that the total TP concentration in roof sediments was more than twice the total TP concentration in road sediments. This difference is caused by the smaller particle size of the roof sediments, as smaller particles contain more TP than the larger sediments. Most of the TP on the dry sediments does not dissolve easily in water and will remain attached to particulates when the particulates enter water.

\subsection{Heavy metal concentrations in filtrate passing through each sieve}

The heavy metal concentrations in the filtrate passing through each sieve are shown on Figure 3(a), (c), and (e). This result shows that the proportions of heavy metals in the sediments from all three sites are similar. For all three sampling sites, the total $\mathrm{Zn}$ concentration is the highest of the six heavy metals investigated, and this is followed by the total $\mathrm{Mn}$ concentration, while the total $\mathrm{Ni}$ concentration is 

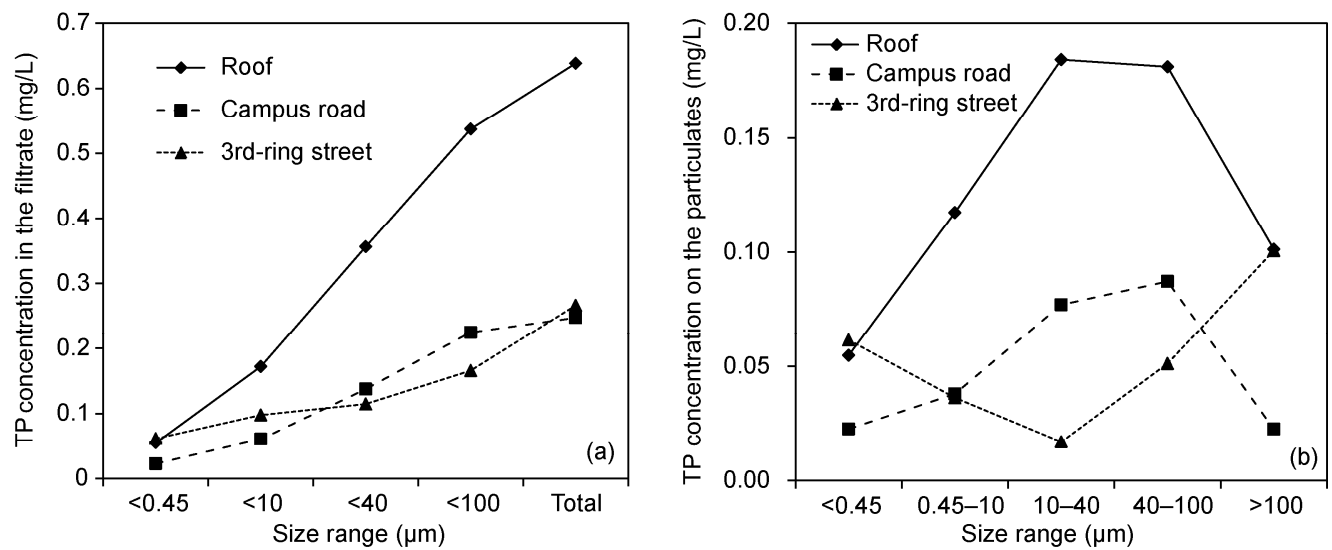

Figure 2 TP concentration in the filtrate passing through each sieve (a) and undesorbable TP concentration on particulates in different size ranges (b).
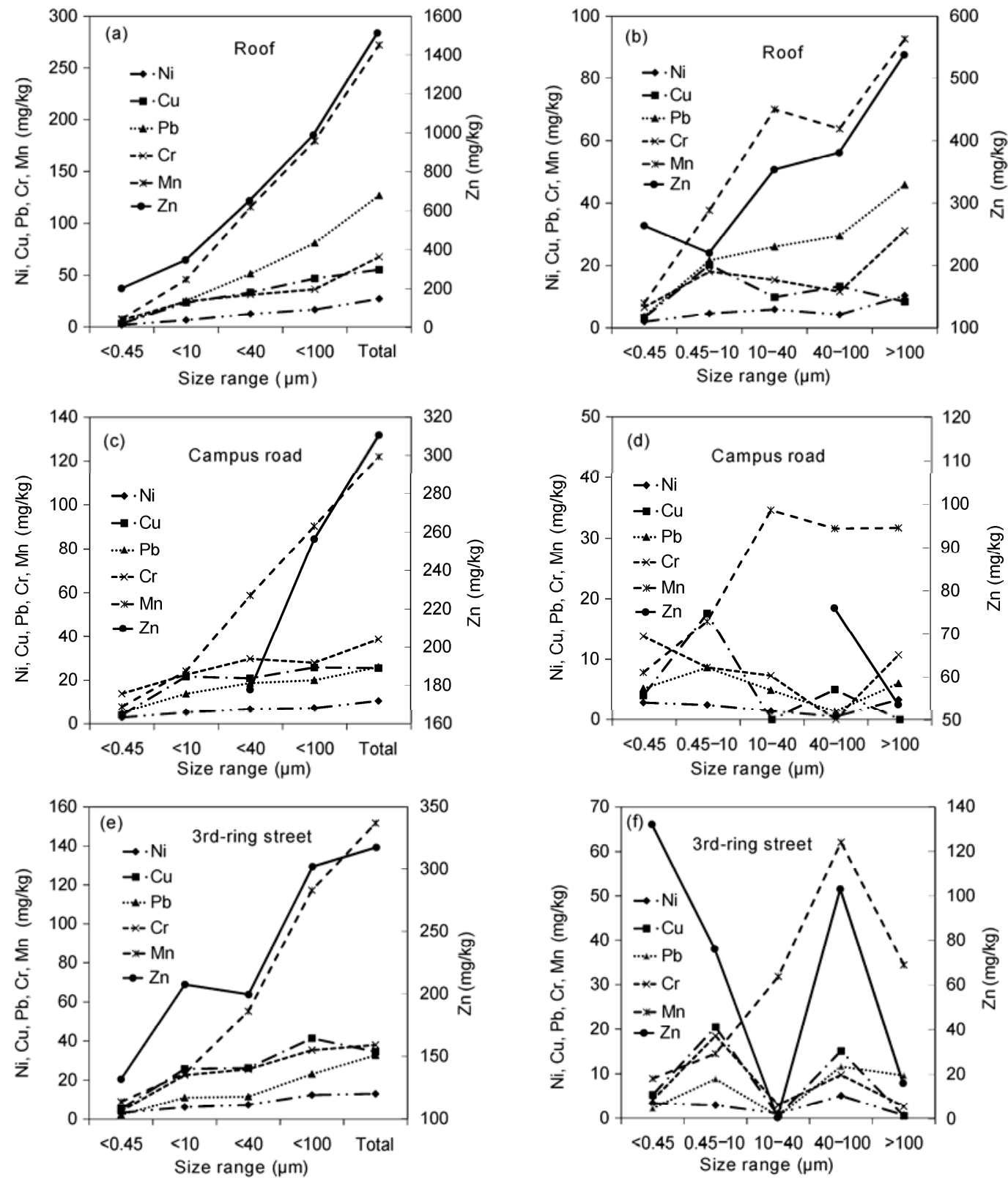

Figure 3 Heavy metal concentrations in the filtrate passing through each sieve (a), (c), (e) and undesorbable heavy metal concentrations on particulates in different size ranges (b), (d), (f). 
the lowest. The orders of the total $\mathrm{Cu}, \mathrm{Pb}$ and $\mathrm{Cr}$ concentrations are more variable. In terms of site differences, the roof sediments have higher heavy metal concentrations than do the road sediments. Figure 3(b), (d), and (f) show the concentrations of particulate heavy metals in different size ranges that cannot be desorbed by the wet sieving procedure. The results show that the roof sediments also have higher undesorbable particulate heavy metal concentrations than do the sediments from the two roads. For the six heavy metals analyzed, $87.0 \%$ to $97.0 \%$ of the total heavy metal mass is present in undesorbable particulate form for the roof sediments, while $68.9 \%$ to $93.6 \%$, and $74.6 \%$ to $94.1 \%$ of the total heavy metals in the campus road and 3rd-ring street, respectively, are in undesorbable particulate form. Therefore, as with TP, heavy metals tend to be bound to particulates and the majority of the heavy metals will not dissolve in water. The concentrations of undesorbable heavy metals in the roof sediments tended to increase with increasing sediment size, but this trend was not observed in the road sediments.

During rainfall events, the dry sediments present on urban surfaces will be flushed into the surrounding water bodies. Pollutants in both dissolved and undesorbable particulate forms will have an adverse effect on those water bodies. The increased nutrient loading, including TP, can cause eutrophication, while the heavy metals can accumulate in living organisms and become toxic. Reducing the input of these pollutants is one of the most important tasks to protect urban water bodies.

For both roof and road sediments, undesorbable particulates form the majority of the pollutant load. This finding suggests that more attention should be paid to the particulates in stormwater runoff, and controlling these particulates will greatly improve the pollutant removal efficiency of stormwater treatment systems. High-efficiency sweeping is an important method of stormwater pollution control in urban area.

\section{Conclusions}

The highest mass proportion for the dry road sediments was between 125 and $300 \mu \mathrm{m}$ in diameter, with $34 \%$ and $39 \%$ for the campus road and 3rd-ring street, respectively. The roof sediments were much smaller with $75 \%$ of the total sediment mass between 40 and $74 \mu \mathrm{m}$. The roof sediments had much higher TP and heavy metal concentrations than did the road sediments. For all three sampling sites, the total
$\mathrm{Zn}$ concentration was the highest of the six heavy metals investigated followed by the total Mn concentration, with the total Ni concentration being the lowest. The concentrations of $\mathrm{Cu}, \mathrm{Pb}$, and $\mathrm{Cr}$ were more variable, but all were between the $\mathrm{Mn}$ and $\mathrm{Ni}$ concentrations for all three sites. After wet sieving, the proportions of undesorbable particulate TP in the sediments were $90.4 \%, 91.0 \%$ and $76.9 \%$ for the roof, the campus road and 3rd-ring street, respectively. Of the six heavy metals analyzed, $87.0 \%$ to $97.0 \%$ from the roof sediment was present in undesorbable particulate form, while from the campus road and 3rd-ring street, $68.9 \%$ to $93.6 \%$ and $74.6 \%$ to $94.1 \%$, respectively, were present in undesorbable particulate form. The concentrations of undesorbable heavy metals tended to increase with increasing sediment size for the roof sediments, but this trend was not found in the road sediments. This study indicates that TP and heavy metals from road and roof sediments are mainly present in undesorbable particulate form in stormwater runoff. Consequently, removing the particulates from stormwater runoff will improve stormwater pollution control.

This work was supported by the National Basic Research Program of Chi$n a$ (2006CB403403), the National Natural Science Foundation for Innovative Research Group (51121003) and the National Natural Science Foundation of China (51278054).

1 Eriksson E, Baun A, Mikkelsen P S, et al. Chemical hazard identification and assessment tool for evaluation of stormwater priority pollutants. Water Sci Technol, 2005, 51: 47-55

2 Kennedy J V, Trompetter W J, Barry B, et al. Elemental analysis of urban stormwater particulate matter by PIXE. Nucl Instrum Methods Phys Res B, 2007, 258: 435-439

3 Garnaud S, Mouchel J M, Chebbo G, et al. Heavy metal concentrations in dry and wet atmospheric deposits in Paris district: Comparison with urban runoff. Sci Total Environ, 1999, 235: 235-245

4 Drapper D, Tomlinson R, Williams P. Pollutant concentrations in road runoff: Southeast Queensland case study. J Environ Eng, 2000, 126: 313-319

5 Tuccillo M E. Size fractionation of metals in runoff from residential an highway storm sewers. Sci Total Environ, 2006, 355: 288-300

6 Davis A P, Shokouhian M, Ni S. Loading estimates of lead, copper, cadmium and zinc in urban runoff from specific sources. Chemosphere, 2001, 44: 997-1009

7 Kim G, Yur J, Kim J. Diffuse pollution loading from urban stormwater runoff in Daejeon city, Korea. J Environ Manag, 2006, 85: 9-16

8 Wang H Q, Zhang S H, Li H Y. Mineral magnetic properties of surface sediments at Bei'anhe, Beijing, and its environmental significance. Chin Sci Bull, 2008, 53: 2536-2546

9 Vaze J, Chiew F H S. Experimental study of pollutant accumulation on an urban road surface. Urban Water, 2002, 4: 379-389

10 Xiang L, Li Y X, Yang Z F, et al. Seasonal difference of heavy metal concentrations and their bioavailability in street dusts in Beijing. $\mathrm{J}$ Environ Sci Health A, 2010, 45: 1092-1100

Open Access This article is distributed under the terms of the Creative Commons Attribution License which permits any use, distribution, and reproduction in any medium, provided the original author(s) and source are credited. 